\title{
A unique co-recovery strategy of cathode and anode from spent $\mathrm{LiFePO}_{4}$ battery
}

\author{
Kai-Di Du ${ }^{1 \dagger}$, Yun-Feng Meng ${ }^{1 \dagger}$, Xin-Xin Zhao ${ }^{1}$, Xiao-Tong Wang ${ }^{2}$, Xiao-Xi Luo ${ }^{1}$, Wei Zhang ${ }^{1}$ and \\ Xing-Long $\mathrm{Wu}^{1,2^{*}}$
}

\begin{abstract}
Along with the explosive growth in the market of new energy electric vehicles, the demand for Li-ion batteries (LIBs) has correspondingly expanded. Given the limited life of LIBs, numbers of spent LIBs are bound to be produced. Because of the severe threats and challenges of spent LIBs to the environment, resources, and global sustainable development, the recycling and reuse of spent LIBs have become urgent. Herein, we propose a novel green and efficient direct recycling method, which realizes the concurrent reuse of $\mathrm{LiFePO}_{4}$ (LFP) cathode and graphite anode from spent LFP batteries. By optimizing the proportion of LFP and graphite, a hybrid LFP/ graphite (LFPG) cathode was designed for a new type of dualion battery (DIB) that can achieve co-participation in the storage of both anions and cations. The hybrid LFPG cathode combines the excellent stability of LFP and the high conductivity of graphite to exhibit an extraordinary electrochemical performance. The best compound, i.e., LFP:graphite $=3: 1$, with the highest reversible capacity $\left(\sim 130 \mathrm{~mA} \mathrm{~h}^{-1}\right.$ at $25 \mathrm{~mA} \mathrm{~g}^{-1}$ ), high voltage platform of $4.95 \mathrm{~V}$, and outstanding cycle performance, was achieved. The specific diffusion behavior of $\mathrm{Li}^{+}$and $\mathrm{PF}_{6}{ }^{-}$in the hybrid cathode was studied using electrode kinetic tests, further clarifying the working mechanism of DIBs. This study provides a new strategy toward the large-scale recycling of positive and negative electrodes of spent LIBs and establishes a precedent for designing new hybrid cathode materials for DIBs with superior performance using spent LIBs.
\end{abstract}

Keywords: $\mathrm{LiFePO}_{4}$, graphite, dual-ion batteries, spent LIBs, recycle

\section{INTRODUCTION}

Because of challenges in achieving the common global desire for reducing emissions caused by global warming and cleaning up the air in urban centers, the decarbonization of personal transportation is important; this change has considerably promoted the process of the electric vehicle (EV) revolution, which is an important measure of the government to fundamentally change the automotive industry [1-4]. As per incomplete statistics, as early as 2017, the annual global EV sales volume has exceeded 1 million for the first time [1]. Lithium-ion batteries (LIBs) are of considerable value in the new energy EV. The demand for and yield of LIBs will sharply increase with the explosive growth of EVs year by year. Among numerous LIBs, olivine-type $\mathrm{LiFePO}_{4}$ (LFP) stands out for its high safety performance, ample storage, good thermal and chemical stability, long cycle life, low cost, and almost non-toxicity [5,6]. Similarly, the extensive excellent characteristics of LFP enable its wide use in heavy-section energy storage devices such as EVs. Furthermore, LFP batteries occupy a dominant position in other electric tools, electric buses, and power-grid energy storage [6]. However, LFP batteries with such a huge market share come along with the explosive increase in the number of spent LIBs and the rapid consumption of natural resources [7]. Moreover, a survey conveys that China alone can produce 500,000 tons of waste LIBs in 2020. By 2030, the world will process an estimated 11 million tons of waste LIBs [8]. Furthermore, the large quantity of discarded LFP batteries has serious hazards, including typical toxic electrolytes, such as $\mathrm{LiPF}_{6}$, dimethyl carbonate (DMC), and other organic solvents [9]. Moreover, the mining and extraction of Li are extremely complicated and expensive, involving 250 tons of spodumene or 750 tons of rich ore brine and 1900 tons of water to produce 1 ton of Li. By comparison, 28 tons of spent LIBs are required to obtain the exact weight of Li through recycling [10]. Therefore, spent LFP has a high recovery value because of its rich Li content. Consequently, turning waste into wealth has become more significant because of many factors such as environment, safety, and resources [11]. In particular, the efficient reclaiming and remanufacturing of waste LIBs can be conducive to recovering high-value materials and substantially alleviate the severe energy consumption problem because of the rapid exploitation of natural resources. However, such processes can reduce the environmental pollution caused by toxic substances from spent LIBs and ultimately promote the sustainable development of LIBs and human society $[12,13]$.

To date, researchers primarily focus on the recovery of valuable metals in nickel-cobalt metal oxides (such as $\mathrm{LiCoO}_{2}$, $\mathrm{LiNi}_{x} \mathrm{Co}_{y} \mathrm{Mn}_{z} \mathrm{O}_{2}$, and $\mathrm{LiNi}_{x} \mathrm{Co}_{y} \mathrm{Al}_{z} \mathrm{O}_{2}$ ) [10]. Commercially used recovery technologies include pyrometallurgy and hydrometallurgy. However, the abovementioned processes generally face multitudinous limitations. For example, hydrometallurgy consumes considerable amounts of corrosive reagents (such as strong acid and strong alkali) for metal leaching and the sub-

\footnotetext{
${ }^{1}$ Faculty of Chemistry, Northeast Normal University, Changchun 130024, China

${ }^{2}$ MOE Key Laboratory for UV Light-Emitting Materials and Technology, Northeast Normal University, Changchun 130024, China

$\dagger$ These authors contributed equally to this work.

* Corresponding author (email: xinglong@nenu.edu.cn)
} 
sequent separation, removal, precipitation, and other steps that are incredibly cumbersome $[14,15]$. Furthermore, most recycling methods only recover the different components of LIBs as simple compounds (lithium carbonate, cobalt oxalate, and nickel oxalate) and inevitably require a considerable amount of polluting wastewater treatment [4,14]. Pyrometallurgy primarily smelts valuable metals into new alloys at high temperatures, consuming extremely high energy. Furthermore, anodes and electrolytes are oxidized and provide energy for the smelting process [16,17]. Moreover, the process emits a considerable amount of polluting greenhouse gases and exerting massive pressure on the environment. Furthermore, the processing of alloys increases the total cost [18]. Despite the operation cost of the abovementioned two methods, reasonable economic benefits can be obtained considering extremely valuable metals. Nevertheless, for LFP batteries without precious metals, the economic benefits generated by the abovementioned traditional methods are insufficient to compensate for the high recovery costs. Therefore, spent LFP batteries should be recycled with improved recycling schemes. Extensive explorations have been conducted to reclaim cathode materials containing high-value metals, whereas several people mentioned the recycling of anode materials. However, with the wide application of high-purity graphite in LIBs owing to its excellent conductivity, high storage capacity, and long cycle stability, and the increasing demand of hundreds of millions of spent LIBs every year, people gradually realize that anode recycling has considerable economic benefits, reducing a series of environmental and waste problems, such as dust pollution caused by direct disposal of landfill or hightemperature incineration of waste anode graphite [19-21]. Furthermore, positive and negative materials are generally recycled separately in the traditional recycling process, and the recycling method is relatively complicated [22-24].

This study proposes an innovative and environmentally friendly method to recycle waste LFP batteries, realizing the double recovery of LFP cathode and graphite anode, and uses them as a new type of hybrid cathode of secondary batteries, namely, LFP/graphite (LFPG) electrode. Moreover, this new hybrid electrode surmounts the limited contribution made by the sufficient amount of electrolyte in traditional LIBs, and it is only used as a medium for single-cation $\left(\mathrm{Li}^{+}\right)$transfer, indicating no extra capacity contribution. Furthermore, the proposed hybrid electrode releases anions in the electrolyte, develops the potential contribution from anions $\left(\mathrm{PF}_{6}^{-}\right)$from the electrolyte to the storage capacity of LIBs, and realizes the function of anions jointly participating in the electrochemical reaction [25-27]. Unlike the "rocking chair" operating mechanism of traditional LIBs, our hybrid electrode realizes the staged insertion/extraction of $\mathrm{Li}^{+}(<4.0 \mathrm{~V})$ and $\mathrm{PF}_{6}^{-}(>4.0 \mathrm{~V})$ in different voltage ranges to enhance the capacity and energy density of existing LIBs [2830]. Theoretically, as a typical olivine-type cathode material, LFP has low ionic and electronic conductivities, which limits the additional development of LFP batteries; its conductivity can be effectively improved by introducing graphite $[31,32]$. Overall, in addition to the high stability of LFP structure and the high conductivity of graphite, the composite electrode LFPG facilitates the lithiation/delithiation process at low voltages $(<4.0 \mathrm{~V})$ and can be used as an ideal cathode for new types of dual-ion batteries (DIBs), thus demonstrating excellent electrochemical performance [33,34]. Accordingly, the composites of LFP and graphite with different proportions were explored, and a hybrid material (LFPG) with optimal electrochemical performance at the ratio of $3: 1$ was obtained. In particular, the composite material $\mathrm{LFP} / \mathrm{G}=3: 1$ maintained a prominent capacity retention rate for 700 cycles at $100 \mathrm{~mA} \mathrm{~g}^{-1}$, indicating its extraordinary long cycle life. Furthermore, the composite material can release an appreciable capacity of $135 \mathrm{~mA} \mathrm{~h} \mathrm{~g}^{-1}$ at $25 \mathrm{~mA} \mathrm{~g}^{-1}$.

\section{EXPERIMENTAL SECTION}

\section{Basic recycling procedures}

Fig. 1 shows the recovery schematic of the spent LFPG battery.

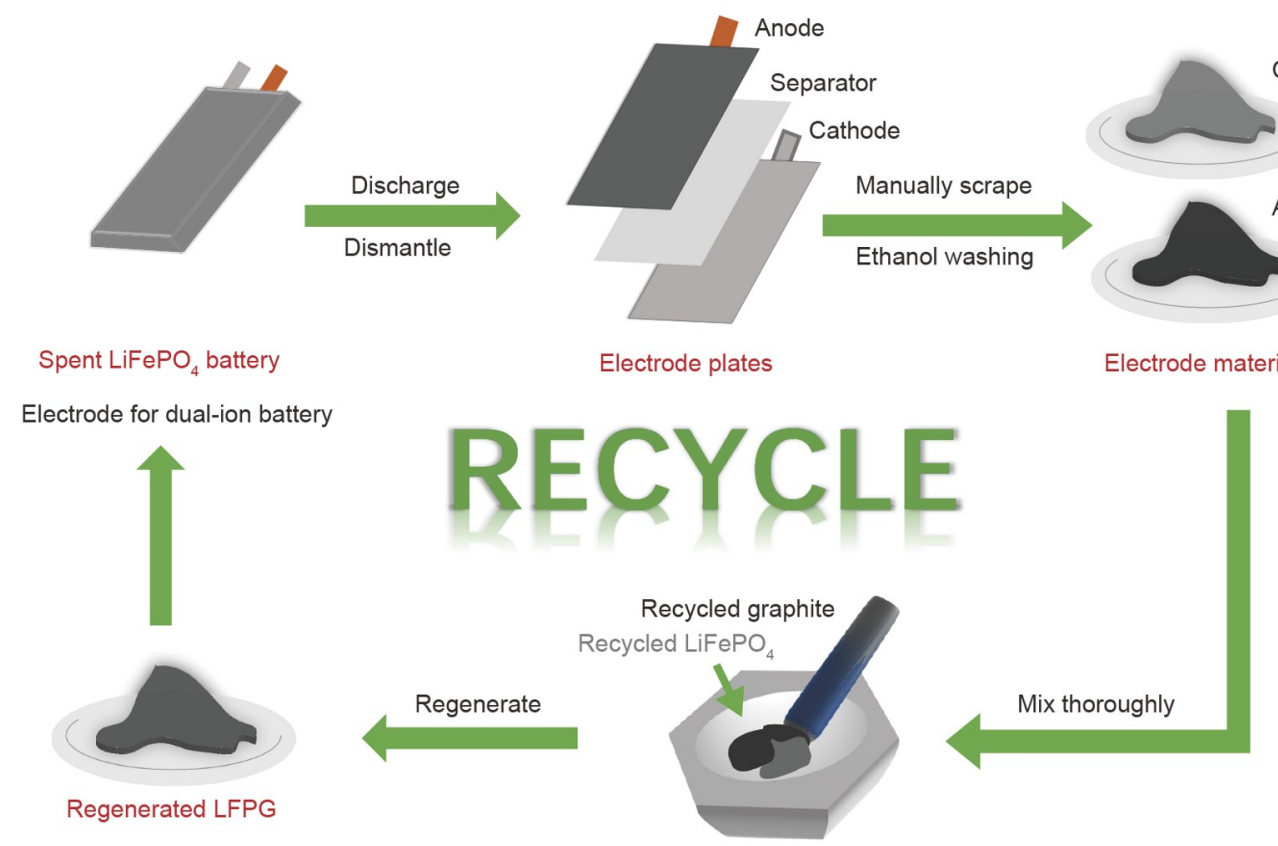

Figure 1 Schematic of the recycling process for the double recovery of the cathode and anode in the spent LFPG battery into a new composite cathode material. 
The spent LFP soft-pack battery originated from a local battery recycling company. For the safety of the battery disassembly process, the spent LFP battery was first pretreated by discharging to $2.0 \mathrm{~V}$. Then, the battery was manually dismantled in the glove compartment to acquire the positive plate, negative plate, separators, polar lug, and Al plastic film shell. Then, the cathode powders (the mixture of LFP, binder, and conductive agent) were obtained by hand scraping from the Al foil, and the graphite anode materials were scratched from the negative plate. Subsequently, the materials were thoroughly washed with water and alcohol to remove the residual electrolyte and other impurities. In particular, graphite was calcinated in a high-temperature furnace at $1300^{\circ} \mathrm{C}$ for $4 \mathrm{~h}$ to ensure the excellent performance of the recycled graphite. Finally, the regenerated electrode material LFPG (LFP:graphite $=1: 3,1: 1,3: 1,5: 1$ ) was synthesized by mixing the recycled LFP and recycled graphite after sufficient grinding at different mass ratios.

\section{Physical and chemical property measurements}

The crystal structure of the regenerated LFPG was characterized using X-ray diffraction (XRD, Rigaku D/MAX-2500). Inductively coupled plasma atomic emission spectrometry (ICP-AES) was applied to measure the elemental contents of the recovered LFP (Table S1). Scanning electron microscopy (SEM, Hitachi SU8000) was performed to observe the morphology and size of all samples and their surface configuration. X-ray photoelectron spectroscopy (XPS) studies were executed on an ESCALab220iXL from VG. Raman spectra (HORIBA) were used to examine the molecular vibration and carbon composition.

\section{Electrochemical property measurements}

To evaluate the electrochemical performance of these materials, we prepared the cathode material by blending the reclaimed LFPG as an active substance with acetylene black (Sigma Aldrich) and sodium alginate (Sigma Aldrich) with the weight ratio of 8:1:1 in deionized water. The resulting slurry was coated on an $\mathrm{Al}$ foil collector and then dried at $60^{\circ} \mathrm{C}$, under vacuum for $8 \mathrm{~h}$. The active substance load was $\sim 1 \mathrm{mg} \mathrm{cm}^{-2}$. The counter electrode was a $\mathrm{Li}$ plate, and $1 \mathrm{~mol} \mathrm{~L}^{-1} \mathrm{LiPF}_{6}$ in ethyl methyl carbonate (EMC, Capchem) was used as the electrolyte. The electrochemical measurements were verified in a CR2032-type coin cell in the voltage range between 2.0 and $5.0 \mathrm{~V}$ versus $\mathrm{Li}^{+} / \mathrm{Li}$ at $25^{\circ} \mathrm{C}$. Galvanostatic charge-discharge (GCD) was implemented on a cell testing device (LAND CT2001A). A VersaSTAT 3 (Princeton Applied Research) electrochemical station was employed to conduct cyclic voltammetry $(\mathrm{CV})$ experiments at various scan rates.

\section{RESULTS AND DISCUSSION}

The material structure and purity of the recycled graphite and LFP were analyzed by XRD. As shown in Fig. 2a, all the diffraction peaks of the recovered LFP correspond to the standard card of the olivine $\mathrm{LiMPO}_{4}(\mathrm{M}=\mathrm{Ni}, \mathrm{Mn}, \mathrm{Fe}, \mathrm{Co})$ with no prominent impurity peaks $[31,35]$, and the recovered graphite displays a strong (002) characteristic peak without other impurity phases, indicating that the recycled LFP and graphite have high purity and excellent crystallinity [36]. In addition,
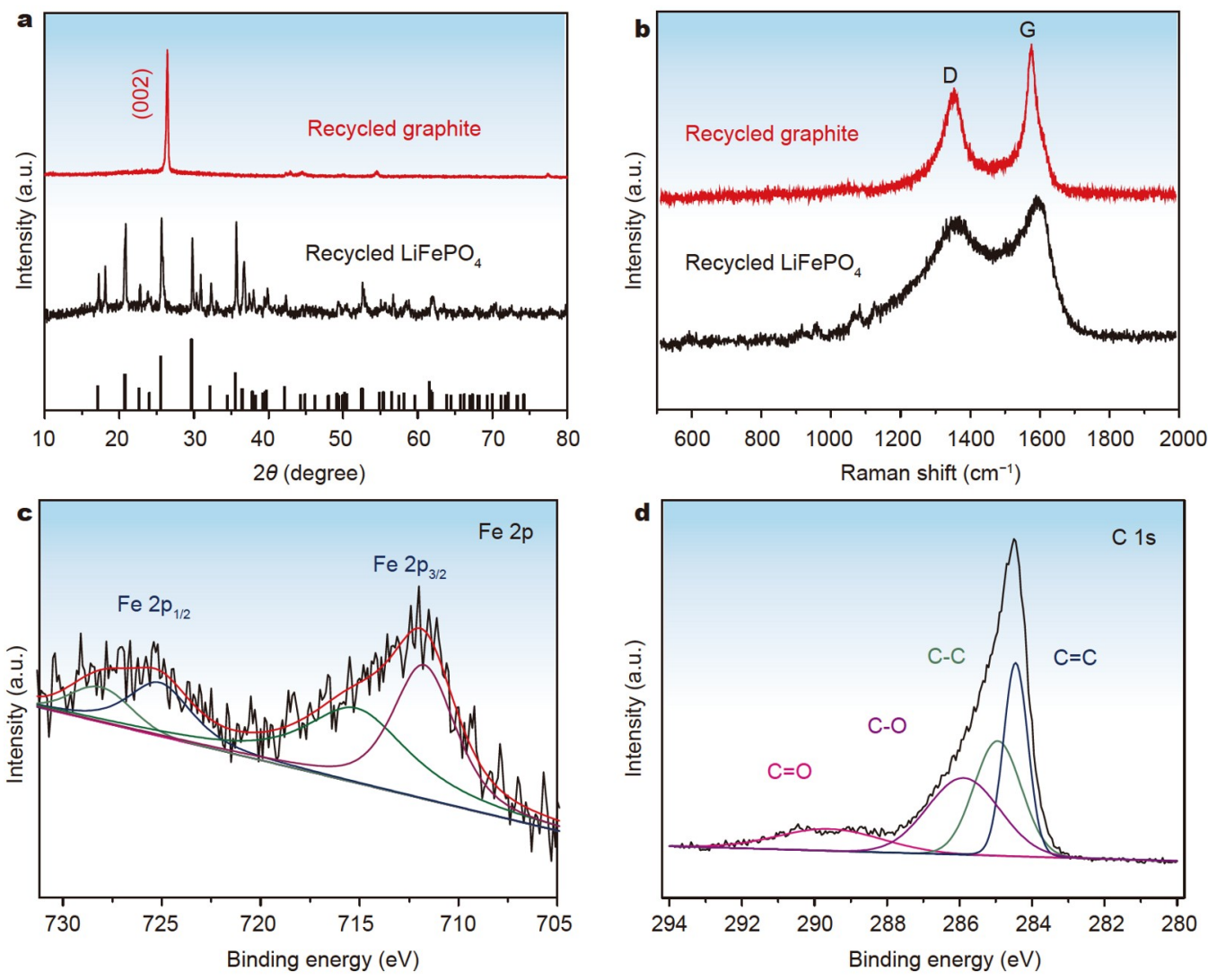

Figure 2 Characterization results of the recycled LFP and recycled graphite: (a) XRD patterns, (b) the corresponding Raman spectra, XPS spectra of (c) Fe 2p for the recycled LFP, and (d) C 1s for the recycled graphite. 
Fig. S1 shows the regenerated LFPG. It can be confirmed that all diffraction peaks are consistent with the corresponding standard card, and there is no obvious impurity phase. Fig. $2 \mathrm{~b}$ shows the Raman spectra of the reclaimed LFP and graphite, in which the vibration of $\mathrm{PO}_{4}{ }^{3-}$ from LFP can be observed in the bands from 600 to $1200 \mathrm{~cm}^{-1}$ [37], and two strong peaks in the wavenumber range of 1200-1450 (D band) and $1500-1650 \mathrm{~cm}^{-1}$ ( $\mathrm{G}$ band) are attributed to the degree of amorphousness and graphitization of carbonaceous materials, respectively. Note that the calculation demonstrates that the intensity ratios between the $\mathrm{D}$ (disorder induced) and $\mathrm{G}$ (graphite induced) bands $\left(I_{\mathrm{D}} / I_{\mathrm{G}}\right)$ in LFP and graphite are 0.90 and 0.79 , respectively, suggesting that the graphitization degrees of recycled LFP and graphite are different. The lower the $I_{\mathrm{D}} / I_{\mathrm{G}}$ is, the better the electronic conductivity and the higher the degree of graphitization [38] are.

Furthermore, the surficial chemical configuration and valence state of elements in LFP and graphite were monitored by XPS. Fig. $2 c$ shows the XPS spectrum of Fe $2 p$ in the recycled LFP. Fe $2 \mathrm{p}_{1 / 2}$ fits the two characteristic peaks corresponding to the position of the binding energy at 715.2/728.1 eV, which relate to the valence state of $\mathrm{Fe}^{3+}$. Similarly, the binding energies located at $711.7 / 725.1 \mathrm{eV}\left(\mathrm{Fe} \mathrm{2} \mathrm{p}_{3 / 2}\right)$ indicate the +2 valence of $\mathrm{Fe}$ in the recycled LFP $[6,39,40]$. As per the XPS results, the Fe in the recycled LFP exists in different valence forms, which is possibly attributed to the disassembly of the spent LFP batteries under a partially charged state. As shown in Fig. 2d, the XPS spectrum of C 1 s of graphite, including four peaks at 284.5, 285.0,285.9, and $289.6 \mathrm{eV}$, can be identified and attributed to the energy level of $\mathrm{C} 1 \mathrm{~s}$ orbitals in $\mathrm{C}=\mathrm{C}, \mathrm{C}-\mathrm{C}, \mathrm{C}-\mathrm{O}$, and $\mathrm{C}=\mathrm{O}$ groups, respectively [41], confirming that the recovered graphite and conductive additives coexist.

The surface morphology and microstructure characteristics of the recycled LFP, graphite, and the regenerated LFPG composite cathode were characterized by SEM (Fig. 3 and Fig. S2). LFP possesses a particle size of $\sim 50-100 \mathrm{~nm}$ and an irregular cubic shape (Fig. 3a). The satisfactory small particle size is conducive to speeding up the extraction and embedding of $\mathrm{Li}^{+}$in the process of electrochemical reaction by decreasing the transmission path of $\mathrm{Li}$ ions, shortening the transportation time, and ultimately endowing the material with an excellent rate performance [42-44]. In addition, such a small particle size of the cathode material endows it with a large specific surface area, which is instrumental in the complete interpenetration between the electrode and electrolyte, thus promoting the adequate diffusion of $\mathrm{Li}$ ions [45]. Moreover, as shown in Fig. 3b, the recovered graphite has a typical layered structure with an approximate size range of several micrometers, indicating that the morphology of the recovered graphite has been restored [21,46]. Fig. 3c, d show the recovered LFP and composite material (LFPG), respectively. The figures demonstrate that the smaller LFP particles are highly dispersed around the larger layered graphite in the sample of the LFPG mixture, thus finally forming the LFPG hybrid electrode (only the recycled composites with recovered LFP and graphite mass ratio of 1:1 are shown here). To show the distribution of elements in the hybrid LFPG material, we measured the energy dispersive X-ray results (Fig. $3 \mathrm{e}-\mathrm{h}$ ). The distribution of Fe coincides with the spatial distribution of $\mathrm{P}$ and $\mathrm{O}$, confirming that the LFP presents in LFPG, whereas graphite and elements, such as $\mathrm{Fe}, \mathrm{O}$, and $\mathrm{P}$, nearly exist in mutual supplements [33]. Therefore, LFP materials are primarily scattered over the vicinity of graphite, thus confirming the results viewed by SEM images.

To evaluate the feasibility of the recycled hybrid LFPG electrode and to examine the extraction/intercalation process of $\mathrm{Li}^{+}$ and $\mathrm{PF}_{6}{ }^{-}$in LFPG, we measured the electrochemical performances of the recycled LFP, graphite, and the hybrid LFPG
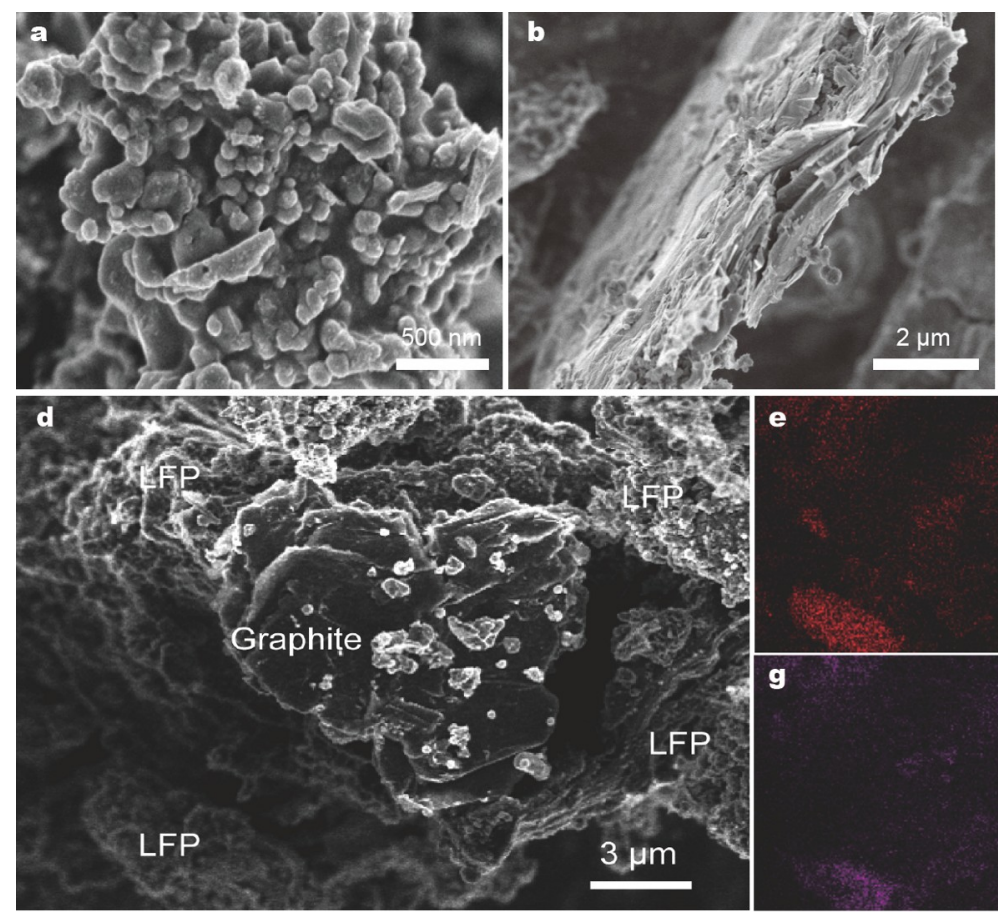

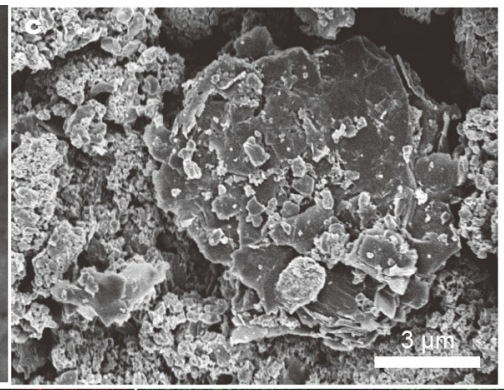

e
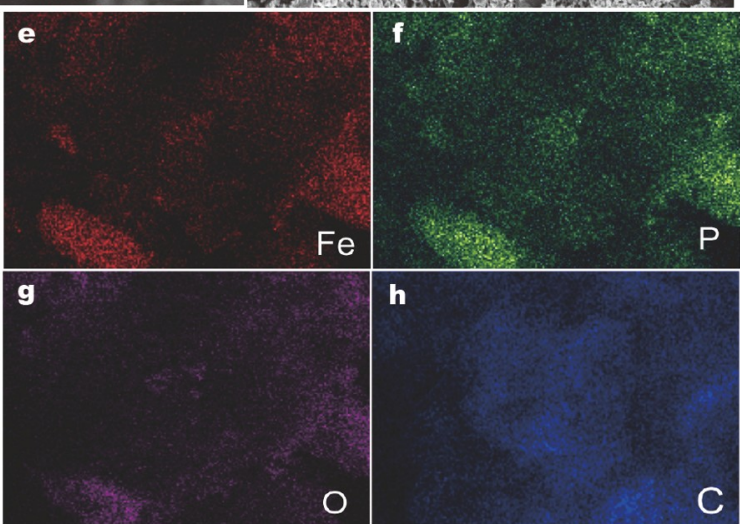

Figure 3 SEM images of (a) the recycled LFP from spent LFPG batteries, (b) the recycled graphite from spent LFPG batteries, (c) the regenerated hybrid material LFPG (LFP:graphite $=1: 1$ ) at different magnifications, and $(\mathrm{d}-\mathrm{h})$ SEM image and energy dispersive X-ray spectroscopy $($ EDX) mapping of the regenerated hybrid LFPG. 
electrodes (LFP:graphite $=1: 1$ ) in coin-type 2032 cells using $\mathrm{Li}$ sheets as the anode in the electrolyte, which comprised $1 \mathrm{~mol} \mathrm{~L}^{-1}$ $\mathrm{LiPF}_{6}$ in DMC. As shown in Fig. 4a, different cells were subjected to the GCD test in a wide voltage window of $2.0-5.0 \mathrm{~V}$ at $25 \mathrm{~mA} \mathrm{~g}^{-1}$. The recycled monomer LFP exhibits one charge/ discharge plateau with a capacity of $123.2 \mathrm{~mA} \mathrm{~h} \mathrm{~g}^{-1}$ at $25 \mathrm{~mA} \mathrm{~g}^{-1}$. The recycled graphite cathode displays several voltage plateaus with a discharge capacity of $79.3 \mathrm{~mA} \mathrm{~h} \mathrm{~g}^{-1}$ at $25 \mathrm{mAg}^{-1}$, which originats from the capacity contributed by the insertion of anions from the electrolyte to graphite layers [21,47]. Furthermore, the hybrid LFPG (LFP:graphite $=1: 1$ ) material can realize a relatively considerable capacity of $99.2 \mathrm{~mA} \mathrm{~h} \mathrm{~g}^{-1}$, which confirms the feasibility of the DIB system based on the hybrid LFPG electrode. The arrow in Fig. 4a shows the contribution of graphite and LFP to the capacity of the composite material. The capacity below $4 \mathrm{~V}$ is primarily contributed by the LFP at $\sim 25 \mathrm{~mA} \mathrm{~h} \mathrm{~g}^{-1}$, whereas that above $4 \mathrm{~V}$ is primarily contributed by the capacity of $\sim 70 \mathrm{~mA} \mathrm{~h} \mathrm{~g}^{-1}$ from graphite.

The hybrid cathode exhibits a multi-step charge process over the extended voltage window from 2.0 to $5.0 \mathrm{~V}$, thus revealing prominent characteristics of both the LFP electrode and graphite electrode from different platforms above 3.45 and $4.0 \mathrm{~V}$ [38]. For investigation, $\mathrm{CV}$ measurements at $0.7 \mathrm{mV} \mathrm{s}^{-1}$ confirm the reversible sequential $\mathrm{Li}^{+}$and $\mathrm{PF}_{6}{ }^{-}$deintercalation/intercalation in stages, a co-working mechanism of the LFPG hybrid electrode (Fig. 4b). A sharp, symmetrical, and pronounced redox peak was observed at $\sim 3.45 \mathrm{~V}$, which benefitted from the extraction/ insertion of $\mathrm{Li}^{+}$in the LFP crystal. However, several redox peaks were detected at $4.0-5.0 \mathrm{~V}$; their intensity was relatively weak and belonged to the migration of $\mathrm{PF}_{6}^{-}$in the graphite phase. Furthermore, the peaks were equivalent to the charge-discharge plateaus in Fig. 4a. Thus, graphite plays an indispensable role that increases the average voltage of the hybrid electrode $[47,48]$.

The detailed diagrammatic sketch in Fig. 5 is delineated to demonstrate the stepwise working mechanism of $\mathrm{Li}^{+}$and $\mathrm{PF}_{6}^{-}$in the hybrid LFPG electrode. In battery charging, $\mathrm{Li}^{+}$was reversibly extracted from the olivine LFP in the voltage range of 2.0$4.0 \mathrm{~V}$ and migrated from the cathode to the anode through the electrolyte. Then, in the high-voltage range of $4.0-5.0 \mathrm{~V}$, the anion $\mathrm{PF}_{6}{ }^{-}$from the electrolyte was released and reversibly intercalated into the layered graphite (Fig. 5). However, during the battery discharge process, $\mathrm{PF}_{6}{ }^{-}$returned from the graphite layer to the electrolyte at a high voltage, and $\mathrm{Li}^{+}$transferred from the anode to the cathode in the low-voltage range and was embedded in the LFP crystal, thus forming a process in which anion/cation participates in the reaction together. Then, the introduction of graphite develops the role of anions in the electrolyte, maximizes the use of all battery parts, further broadens the voltage and strengthens the energy density of the hybrid electrode.

The GCD was conducted first to examine the electrochemical performance and cycle stability of the hybrid LFPG cathode with the best ratio. As shown in Fig. 6a, the initial GCD curves of the hybrid electrode with different mass ratios (LFP:graphite $=1: 3$, $1: 1,3: 1,5: 1)$ were compared at $25 \mathrm{mAg}^{-1}$. The above hybrid cathodes of different proportions demonstrate the characteristics of typical LFP and graphite, which can be confirmed using different voltage platforms. For all samples, $L F P / G=3: 1$ and $\mathrm{LFP} / \mathrm{G}=5: 1$ show excellent discharge specific capacities, which are similar to the capacity of $135.0 \mathrm{~mA} \mathrm{~h} \mathrm{~g}^{-1}$ at $25 \mathrm{~mA} \mathrm{~g}^{-1}$. Furthermore, $\mathrm{LFP} / \mathrm{G}=1: 1$ and $\mathrm{LFP} / \mathrm{G}=1: 3$ provide relatively lower capacities of 99.6 and $89.5 \mathrm{~mA} \mathrm{~h} \mathrm{~g}^{-1}$ at $25 \mathrm{~mA} \mathrm{~g}^{-1}$, respectively. Therefore, with increase in the ratio of LFP, the discharge capacities of the hybrid electrode gradually increase, which may be attributed to the considerably higher discharge capacity of the LFP cathode $\left(\sim 125 \mathrm{~mA} \mathrm{~h} \mathrm{~g}^{-1}\right.$, Fig. $\left.4 \mathrm{a}\right)$ compared with the discharge capacity of the graphite cathode $\left(\sim 80 \mathrm{~mA} \mathrm{~h}^{-1}\right.$, Fig. $\left.4 \mathrm{a}\right)$ $[33,49]$. Second, as visualized in Fig. $6 \mathrm{~b}$, the rate capabilities of LFPG with different mass ratios and the recycled LFP and graphite were compared by GCD at various current densities. The significantly reduced discharge capacity ( $\sim 56 \%$ capacity retention) at a high current density of $1 \mathrm{~A} \mathrm{~g}^{-1}$ suggests the inferior rate capability of the recovered LFP, which is possibly consistent with the sluggish diffusion of Li ions caused by the poor conductivity of the olivine-type LFP [49].

By comparison, the graphite cathode with inherent excellent electrical conductivity exhibits an expected higher rate performance than the recycled LFP. In particular, the graphite cathode can reach a relatively appreciable capacity retention rate $(\sim 90 \%)$ at $1 \mathrm{Ag}^{-1}$. Note that, under the conditions of the current intensities of $25,50,100,200,500$, and $1000 \mathrm{~mA} \mathrm{~g}^{-1}$, the hybrid cathode LFPG with the composition ratio of LFP:graphite $=3: 1$ (by weight) delivered capacities of 134.9, 128.9, 121.7, 114.0, 102.8 , and $87.4 \mathrm{~mA} \mathrm{~h} \mathrm{~g}^{-1}$, respectively. Importantly, after high-
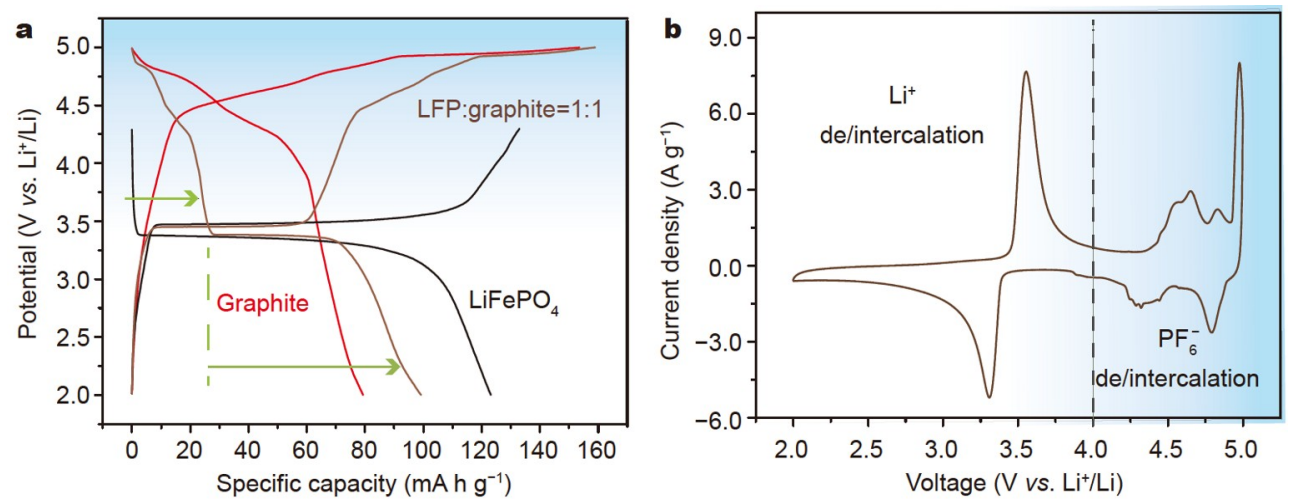

Figure 4 Electrochemical characterizations of different electrodes in half-cells at $25 \mathrm{mAg}^{-1}$. (a) Charge-discharge profiles of the first cycle of the recycled LFP electrode, graphite, and regenerated LFPG (LFP:graphite $=1: 1)$ in $1 \mathrm{~mol} \mathrm{~L}^{-1} \mathrm{LiPF}_{6} / \mathrm{EMC}$ between 2.0 and $5.0 \mathrm{~V}_{\left(\mathrm{Li}^{+}\right.}$and $\mathrm{PF}_{6}{ }^{-}$contributions were separated by different regions). Hybrid LFPG electrode: the white part represents the contribution from the de/intercalation of cation $\mathrm{Li}^{+}$in $\mathrm{LFP}$, and the blue area denotes the contribution from the de/intercalation of anion $\mathrm{PF}_{6}{ }^{-}$in graphite; different capacity contributions have been marked with arrows. (b) $\mathrm{CVs}$ of the regenerated hybrid LFPG electrode at $0.7 \mathrm{mV} \mathrm{s}^{-1}$. 


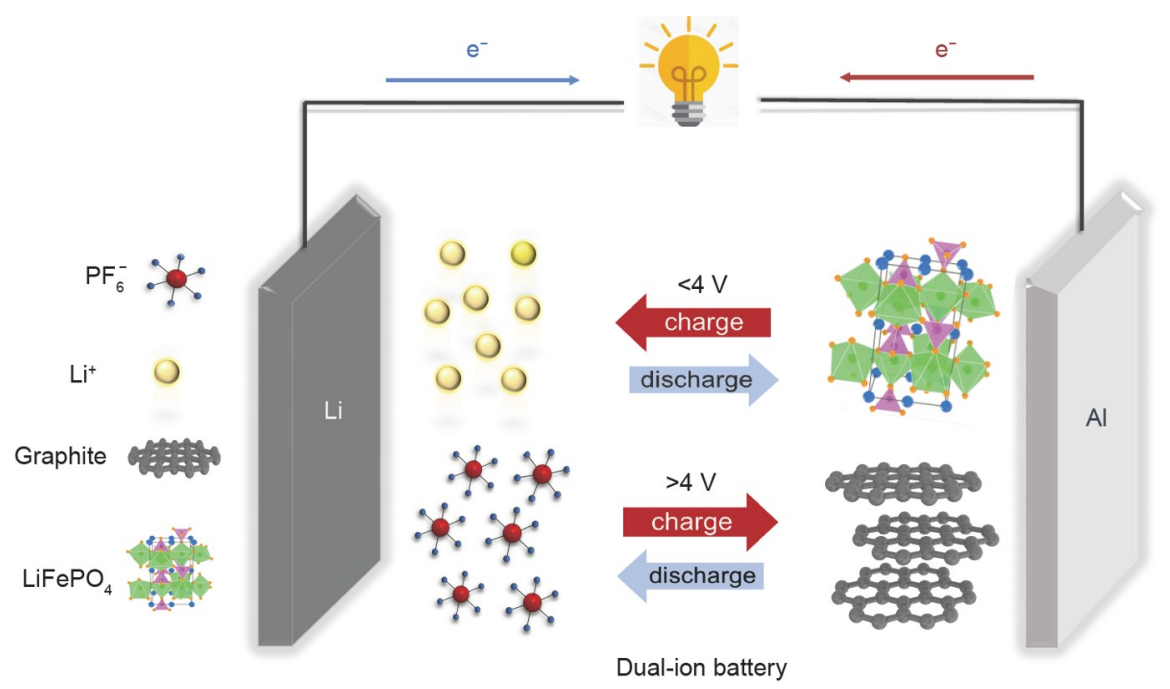

Figure 5 Schematic of the working mechanism of the Li/LFPG dual-ion hybrid battery, in which the extraction/insertion of $\mathrm{Li}^{+}$and $\mathrm{PF}_{6}{ }^{-}$occurred in stages, with $\mathrm{Li}^{+}$for the low-voltage range $(<4.0 \mathrm{~V})$ and $\mathrm{PF}_{6}{ }^{-}$for the high-voltage window $(>4.0 \mathrm{~V})$.
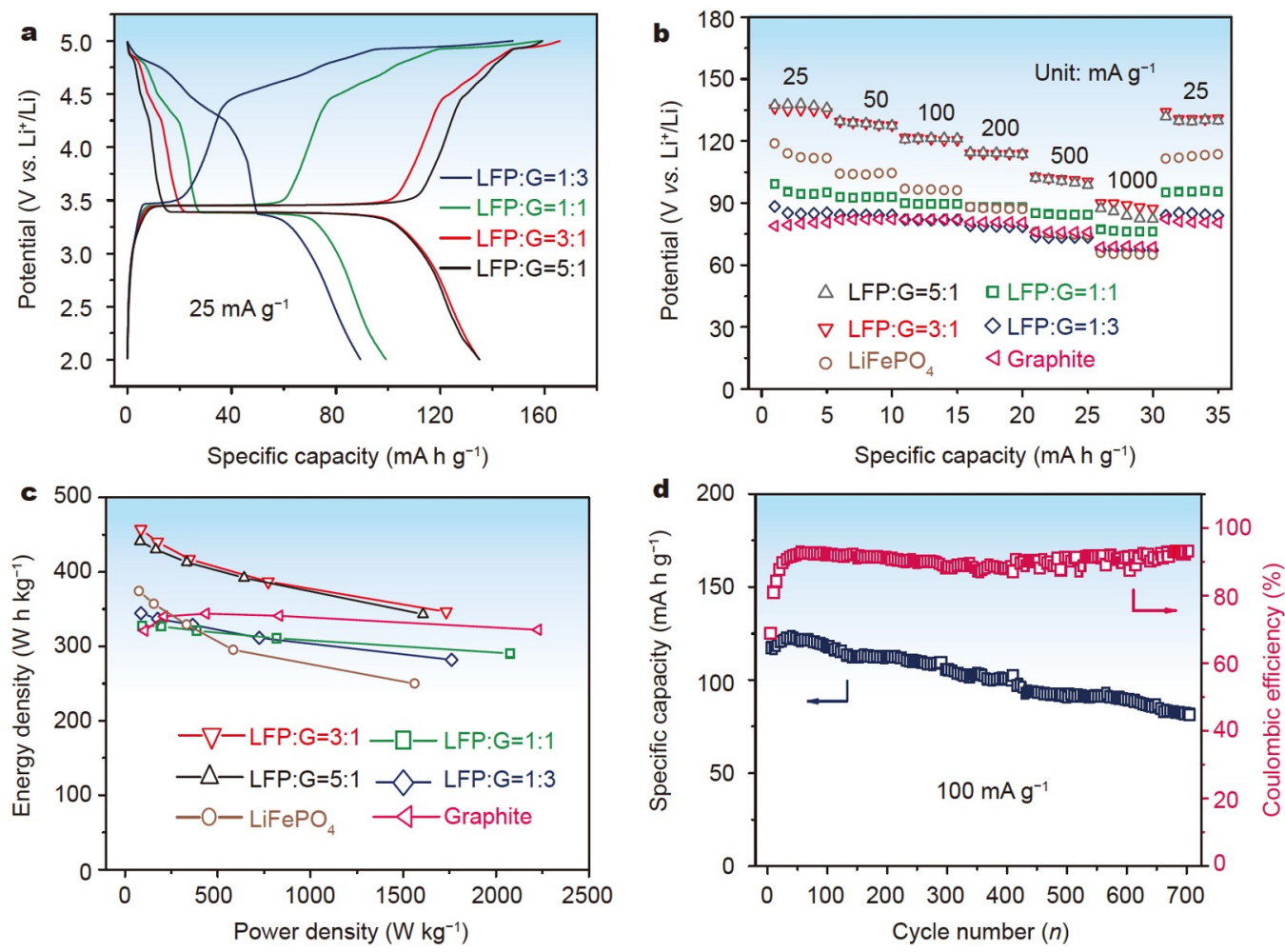

Figure 6 Electrochemical comparison of different electrodes in half-cells tested in 2.0-5.0 Vvs. $\mathrm{Li}^{+} / \mathrm{Li}$. (a) GCD tests of the regenerated LFPG composites with four different mass ratios during the first cycle at $25 \mathrm{~mA} \mathrm{~g}^{-1}$; (b) rate capacities of the recycled LFP, graphite, and the regenerated hybrid LFPG electrodes with different mass ratios at various current intensities. (c) The corresponding Ragone plot of different electrodes; (d) long-term cycling stabilities (black arrow) and coulombic efficiency (red arrow) of the regenerated hybrid LFPG (LFP:G $=3: 1$ ) electrode at $100 \mathrm{~mA} \mathrm{~g}^{-1}$ for 700 cycles.

current-density cycling, the current density dropped to $25 \mathrm{~mA} \mathrm{~g}^{-1}$; however, it still delivered a considerable capacity of $134.1 \mathrm{~mA} \mathrm{~h}^{-1}$, which can almost be returned to the original specific discharge capacity, indicating the superior reversible costorage of anions and cations in the mixed material and the distinguished structural stability of the two hosts (LFP and graphite). All the abovementioned performances are better than those of the recovered LFP and graphite.
The remarkable improvements in the capacity and rate performance of LFPG hybrid electrodes can be attributed to their distinctive structure and morphology, which optimize the conductivity and abate the polarization of the electrochemical process. Furthermore, the performance of the hybrid cathode LFPG with the mass ratio of LFP:graphite $=5: 1$ is comparable to that of the hybrid cathode LFPG with the mass ratio of LFP:graphite = 3:1 and higher than that of other hybrid materials. However, 
LFP:graphite $=3: 1$ still obtains a discharge specific capacity of $87.4 \mathrm{mAhg}^{-1}$ at a high current density of $1 \mathrm{Ag}^{-1}$, and this capacity is superior to that of LFP:graphite $=5: 1$ with $82.2 \mathrm{~mA} \mathrm{~h} \mathrm{~g}^{-1}$ discharge capacity (the capacity retention rates of different materials are $64.7 \%$ for LFP:graphite $=3: 1$ and $59.7 \%$ for LFP:graphite $=5: 1$ at $\left.1 \mathrm{Ag}^{-1}\right)$. Furthermore, the rate capability of LFP:graphite $=3: 1$ is better than that of other regenerated hybrid LFPG electrodes under different mass ratios. The extraordinary capacity of hybrid materials with a high current density should be attributed to the introduction of a graphite material, which facilitates the relative stability under high current density. Furthermore, this capacity compensates for the inherent limitations of the low conductivity of recovered LFP, thereby obtaining excellent rate capability [50]. Theoretically, the higher the ratio of LFP with a high theoretical specific capacity $\left(\sim 170 \mathrm{~mA} \mathrm{~h} \mathrm{~g}^{-1}\right)$, the higher the discharge capacity that can be provided. Nevertheless, the increased capacity degradation of LFP at a high current density must be addressed [6]. Based on the abovementioned analysis, in balancing the high capacity of LFP and the high conductivity of graphite, the best composite material that can play the optimal rate performance is LFP:G $=3: 1$. To highlight the best electrochemical performance of the composite LFP:G $=3: 1$, we performed the comparative test of Ragone plots (energy density and power density) (Fig. 6c). The energy density and power density of the recycled LFP were poorer. However, the composite LFP:G $=3: 1$ exhibited an encouraging power density as high as $\sim 1700 \mathrm{~W} \mathrm{~kg}^{-1}$ when the energy density was $350 \mathrm{Wh} \mathrm{kg}^{-1}$, and this power density is superior to those of other hybrid materials (graphite can obtain better power density under a high current density, which considerably benefits the relative stability of the graphite material [26]).

Furthermore, the hybrid LFPG electrode exhibits prominent cyclic stability (Fig. 6d). Remarkably, the capacity of the regenerated LFPG with the weight ratio of LFP:graphite $=3: 1$ decayed from 120.6 to $92.8 \mathrm{~mA} \mathrm{~h} \mathrm{~g}^{-1}$ under the constant current condition of $100 \mathrm{~mA} \mathrm{~g}^{-1}$ for 700 cycles. Moreover, the capacity retention rate was up to $76.9 \%$, and the average capacity attenuation per cycle was $0.039 \mathrm{~mA} \mathrm{~h} \mathrm{~g}^{-1}$, confirming that the olivine-type LFP and layered graphite in the composites maintained excellent structural stability during the stepwise extraction/insertion of $\mathrm{Li}^{+}$and $\mathrm{PF}_{6}^{-}$, thus obtaining an extraordinary cycling performance. However, the initial coulombic efficiency (CE) of this material was lower compared with that of traditional cathode materials. The primary reasons are listed below. Compared with traditional cathode materials, the redox reactions of anion de-/intercalation on the graphite cathode usually occurr at a high potential (nearly or higher than $5.0 \mathrm{~V}$ versus $\mathrm{Li}^{+} / \mathrm{Li}$ ), which exceeds the anodic stable window of conventional carbonate electrolytes. Furthermore, serious side reactions, such as the decomposition of electrolyte under a high voltage and unknown irreversible electrochemical reactions, usually occur during the anion de-/intercalation, which leads to a very low $\mathrm{CE}$ [22].

To confirm the feasibility of our recycling method, we selected a group of composite materials with the best electrochemical performance. We compared the electrochemical performance of the composite electrode (LFPG) from the spent LIBs and the hybrid cathode using commercially available cathode and anode. As shown in Fig. S3, the cycle performance and discharge specific capacity of these two hybrid materials are close, proving the feasibility of our recovery method.

The CV test of hybrid LFPG materials at various scan rates was implemented under voltages between 2.0 and $5.0 \mathrm{~V}$ (Fig. S4). Fig. S4a, c, e, and g show the CV curves of the hybrid LFPG materials with different mass ratios (LFP:G $=1: 1,1: 3,3: 1,5: 1$ ) at the scan rate from 0.1 to $0.7 \mathrm{mV} \mathrm{s}^{-1}$. All four pairs of redox peaks at different ratios of the composite LFPG materials (namely, O1/ $\mathrm{R} 1$ for LFP with $\mathrm{Li}^{+}$extraction/insertion; O2/R2, O3/R3, and O4/ $\mathrm{R} 4$ for layered graphite with $\mathrm{PF}_{6}{ }^{-}$de-/intercalation) have similar positions. The intensity of the characteristic peaks at $>3.45$ and $4.0 \mathrm{~V}$ significantly changed, and it was attributed to the difference in the LFP content and graphite in the various hybrid materials. As shown in Fig. S4b, d, f, and h, the corresponding $\mathrm{CV}$ curves were used to fit the linear relationship among the peak current densities $\left(i_{\mathrm{p}}\right)$ and the square root of scan rates $\left(v^{1 / 2}\right)$ of the composite with different proportions. From the linear fitting results, the reaction process of $\mathrm{Li}^{+}$and $\mathrm{PF}_{6}^{-}$in the extraction/insertion process is a diffusion-controlled process. Furthermore, the apparent diffusion coefficients $\left(D_{\text {app }}\right)$ of $\mathrm{Li}^{+}$ and $\mathrm{PF}_{6}{ }^{-}$were obtained through the $\mathrm{CV}$ curve results to evaluate the migration kinetics characteristics of the cation/anion in the hybrid LFPG electrode more accurately on the basis of the Randles-Sevcik equation [38].

$i_{p}=2.69 \times 105 n^{3 / 2} A D_{\text {app }}^{1 / 2} v^{1 / 2} C_{0}$,

where $A$ is the actual area of the cathode material, $n$ is the number of electrons in every reaction species, $D_{\text {app }}$ is the apparent diffusion coefficients of $\mathrm{Li}^{+} / \mathrm{PF}_{6}^{-}$, and $C_{0}$ is the concentration of $\mathrm{Li}^{+} / \mathrm{PF}_{6}^{-}$in the cathode for $D_{\text {app }}\left(\mathrm{Li}^{+}\right) / D_{\text {app }}\left(\mathrm{PF}_{6}^{-}\right)$ calculation. The detailed calculation of the value of each point is shown in the Supplementary information (Table S2).

Importantly, the diffusion coefficients of cation $\mathrm{Li}^{+}$and anion $\mathrm{PF}_{6}^{-}$are of the order of $10^{-10}$ to $10^{-12}$ from the strong comparison of these data, indicating that $\mathrm{Li}^{+}$and $\mathrm{PF}_{6}^{-}$have excellent dynamic diffusion behavior. In particular, the diffusion coefficient of $\mathrm{Li}^{+}$reaches the maximum value of $3.75 \times 10^{-10} \mathrm{~cm}^{2} \mathrm{~s}^{-1}$ in $\mathrm{LFP} / \mathrm{G}=3: 1$ as the content of LFP in the composite material LFPG gradually increases, which corresponds well to the previous rate capability and confirms that the deintercalation and intercalation reactions of $\mathrm{Li}^{+}$and $\mathrm{PF}_{6}^{-}$are significantly different processes. In general, the $D_{\text {app }}\left(\mathrm{Li}^{+}\right)$values corresponding to $\mathrm{Li}^{+}$ diffusion in LFP reported before are in the $10^{-12}$ to $10^{-14}$ orders of magnitude; these two orders are lower than the regenerated hybrid LFPG material in this study, primarily owing to the introduction of conductive graphite in the hybrid cathode [32].

\section{CONCLUSIONS}

In total, we proposed an innovative and green process for the recycling and reuse of spent LFP batteries, thus adding the concept of DIBs and meticulously designed hybrid LFPG materials, which integrated the cathode LFP and anode graphite from the spent LFP battery into the cathode material of the new DIB. The proposed material realizes both the double recovery of the cathode and anode to the greatest extent and takes advantage of the excellent electrochemical performance of the DIB, such as enhanced rate capability, high energy density, and encouraging cycle performance, benefiting greatly from the complementation of LFP and graphite. The inherent high-capacity characteristics of the LFP cathode $\left(\sim 140 \mathrm{~mA} \mathrm{~h} \mathrm{~g}^{-1}\right)$ were significantly highlighted. The introduction of graphite with high conductivity and voltage (the most elevated voltage platform was $\sim 4.95 \mathrm{~V}$ ), com- 
pensating for the intrinsic weakness of traditional phosphate cathodes of poor conductivity. Compared with conventional "rocking chair" batteries, this composite electrode lacks anion contribution. In addition to $\mathrm{Li}^{+}$for extraction/intercalation, $\mathrm{PF}_{6}{ }^{-}$ in the electrolyte undergoes intercalation reaction on the graphite to contribute some of the additional capacity. Moreover, the exploration of the different mass ratios of composite cathode demonstrated that the LFP:graphite $=3: 1$ hybrid electrode provided the best electrochemical performance. In particular, the composite material LFP:graphite $=3: 1$ maintained a wonderful capacity retention rate for 700 cycles at a current density of $100 \mathrm{mAg}^{-1}$ and provided the highest capacity close to $130 \mathrm{~mA} \mathrm{~h} \mathrm{~g}^{-1}$ at $25 \mathrm{~mA} \mathrm{~g}^{-1}$. Furthermore, the kinetic analysis of the hybrid LFPG demonstrated that the extraction/intercalation of $\mathrm{Li}^{+}$and $\mathrm{PF}_{6}{ }^{-}$was performed in different stages during the electrochemical reaction. Two different diffusion modes were observed between the low-voltage $(<4.0 \mathrm{~V})$ and high-voltage scope $(>4.0 \mathrm{~V})$. The DIB cathode material LFPG in this research is based on the olivine-type LFP and the layered graphite; it is used to deliver a brilliant electrochemical performance. Furthermore, the proposed material provides a new idea for largescale, green, efficient, and environmentally friendly reclaiming and reuse of spent LIBs in the industry, which can be extended to other spent LIBs and be of great interest for sustainable development of next LIBs.

\section{Received 24 June 2021; accepted 13 August 2021; published online 23 September 2021}

1 Harper G, Sommerville R, Kendrick E, et al. Recycling lithium-ion batteries from electric vehicles. Nature, 2019, 575: 75-86

2 Chen M, Ma X, Chen B, et al. Recycling end-of-life electric vehicle lithium-ion batteries. Joule, 2019, 3: 2622-2646

3 Fan E, Li L, Wang Z, et al. Sustainable recycling technology for Li-ion batteries and beyond: Challenges and future prospects. Chem Rev, 2020, 120: 7020-7063

4 Ciez RE, Whitacre JF. Examining different recycling processes for lithium-ion batteries. Nat Sustain, 2019, 2: 148-156

$5 \mathrm{Yu}$ J, Wang $\mathrm{X}$, Zhou $\mathrm{M}$, et al. A redox targeting-based material recycling strategy for spent lithium ion batteries. Energy Environ Sci, 2019, 12: 2672-2677

6 Shin EJ, Kim S, Noh JK, et al. A green recycling process designed for $\mathrm{LiFePO}_{4}$ cathode materials for Li-ion batteries. J Mater Chem A, 2015, 3: $11493-11502$

7 Sun Q, Li X, Zhang $\mathrm{H}$, et al. Resynthesizing $\mathrm{LiFePO}_{4} / \mathrm{C}$ materials from the recycled cathode via a green full-solid route. J Alloys Compd, 2020, 818: 153292

8 Natarajan S, Aravindan V. Burgeoning prospects of spent lithium-ion batteries in multifarious applications. Adv Energy Mater, 2018, 8: 1802303

9 Costa CM, Barbosa JC, Gonçalves R, et al. Recycling and environmental issues of lithium-ion batteries: Advances, challenges and opportunities. Energy Storage Mater, 2021, 37: 433-465

$10 \mathrm{Wu} J$, Mackenzie A, Sharma N. Recycling lithium-ion batteries: Adding value with multiple lives. Green Chem, 2020, 22: 2244-2254

11 Zhang X, Li L, Fan E, et al. Toward sustainable and systematic recycling of spent rechargeable batteries. Chem Soc Rev, 2018, 47: 7239-7302

12 Tran MK, Rodrigues MTF, Kato K, et al. Deep eutectic solvents for cathode recycling of Li-ion batteries. Nat Energy, 2019, 4: 339-345

13 Lv W, Wang Z, Cao $\mathrm{H}$, et al. A critical review and analysis on the recycling of spent lithium-ion batteries. ACS Sustain Chem Eng, 2018, 6: 1504-1521

14 Yao Y, Zhu M, Zhao Z, et al. Hydrometallurgical processes for recycling spent lithium-ion batteries: A critical review. ACS Sustain Chem Eng, 2018, 6: 13611-13627
15 Yi AF, Zhu ZW, Liu YH, et al. Using highly concentrated chloride solutions to leach valuable metals from cathode-active materials in spent lithium-ion batteries. Rare Met, 2020, 40: 1971-1978

16 Lin J, Li L, Fan E, et al. Conversion mechanisms of selective extraction of lithium from spent lithium-ion batteries by sulfation roasting. ACS Appl Mater Interfaces, 2020, 12: 18482-18489

17 Arshad F, Li L, Amin K, et al. A comprehensive review of the advancement in recycling the anode and electrolyte from spent lithium ion batteries. ACS Sustain Chem Eng, 2020, 8: 13527-13554

18 Xiao J, Li J, Xu Z. Challenges to future development of spent lithium ion batteries recovery from environmental and technological perspectives. Environ Sci Technol, 2019, 54: acs.est.9b03725

19 Natarajan S, Aravindan V. An urgent call to spent LIB recycling: Whys and wherefores for graphite recovery. Adv Energy Mater, 2020, 10: 2002238

20 Liang HJ, Hou BH, Li WH, et al. Staging Na/K-ion de-/intercalation of graphite retrieved from spent $\mathrm{Li}$-ion batteries: In operando X-ray diffraction studies and an advanced anode material for $\mathrm{Na} / \mathrm{K}$-ion batteries. Energy Environ Sci, 2019, 12: 3575-3584

21 Li WH, Ning QL, Xi XT, et al. Highly improved cycling stability of anion de-/intercalation in the graphite cathode for dual-ion batteries. Adv Mater, 2019, 31: 1804766

22 Natarajan S, Boricha AB, Bajaj HC. Recovery of value-added products from cathode and anode material of spent lithium-ion batteries. Waste Manage, 2018, 77: 455-465

23 Li J, Zhong S, Xiong D, et al. Synthesis and electrochemical performances of $\mathrm{LiCoO}_{2}$ recycled from the incisors bound of $\mathrm{Li}$-ion batteries. Rare Met, 2009, 28: 328-332

24 Zhao Y, Fang LZ, Kang YQ, et al. A novel three-step approach to separate cathode components for lithium-ion battery recycling. Rare Met, 2021, 40: 1431-1436

25 Hao J, Yang F, Zhang S, et al. Designing a hybrid electrode toward high energy density with a staged $\mathrm{Li}^{+}$and $\mathrm{PF}_{6}{ }^{-}$deintercalation/intercalation mechanism. Proc Natl Acad Sci USA, 2020, 117: 2815-2823

26 Yang C, Chen J, Ji X, et al. Aqueous Li-ion battery enabled by halogen conversion-intercalation chemistry in graphite. Nature, 2019, 569: 245250

27 Zhou X, Liu Q, Jiang C, et al. Strategies towards low-cost dual-ion batteries with high performance. Angew Chem Int Ed, 2020, 59: 3802 3832

28 Zeng Z, Liu X, Jiang X, et al. Enabling an intrinsically safe and highenergy-density $4.5 \mathrm{~V}$-class Li-ion battery with nonflammable electrolyte. InfoMat, 2020, 2: 984-992

29 Zhang SS. Design aspects of electrolytes for fast charge of Li-ion batteries. InfoMat, 2021, 3: 125-130

30 Heng Y, Gu Z, Guo J, et al. Research progresses on vanadium-based cathode materials for aqueous zinc-ion batteries. Acta Physico Chim Sin, 2020, 0: 2005013

31 Yang Y, Guo JZ, Gu ZY, et al. Effective recycling of the whole cathode in spent lithium ion batteries: From the widely used oxides to highenergy/stable phosphates. ACS Sustain Chem Eng, 2019, 7: acssuschemeng.9b00526

32 Li Z, Yang J, Guang T, et al. Controlled hydrothermal/solvothermal synthesis of high-performance $\mathrm{LiFePO}_{4}$ for $\mathrm{Li}$-ion batteries. Small Methods, 2021, 5: 2100193

33 Li F, Tao R, Tan X, et al. Graphite-embedded lithium iron phosphate for high-power-energy cathodes. Nano Lett, 2021, 21: 2572-2579

34 Rodríguez-Pérez IA, Zhang L, Wrogemann JM, et al. Enabling natural graphite in high-voltage aqueous graphite||Zn metal dual-ion batteries. Adv Energy Mater, 2020, 10: 2001256

35 Liu K, Tan Q, Liu L, et al. Acid-free and selective extraction of lithium from spent lithium iron phosphate batteries via a mechanochemically induced isomorphic substitution. Environ Sci Technol, 2019, 53: 97819788

36 Guo H, Wu C, Xie J, et al. Controllable synthesis of high-performance $\mathrm{LiMnPO}_{4}$ nanocrystals by a facile one-spot solvothermal process. J Mater Chem A, 2014, 2: 10581-10588

$37 \mathrm{Gu} \mathrm{ZY}$, Guo JZ, Sun ZH, et al. Carbon-coating-increased working voltage and energy density towards an advanced $\mathrm{Na}_{3} \mathrm{~V}_{2}\left(\mathrm{PO}_{4}\right)_{2} \mathrm{~F}_{3} @ \mathrm{C}$ 
cathode in sodium-ion batteries. Sci Bull, 2020, 65: 702-710

38

Meng YF, Liang HJ, Zhao CD, et al. Concurrent recycling chemistry for cathode/anode in spent graphite/ $/ \mathrm{LiFeO}_{4}$ batteries: Designing a unique cation/anion-co-workable dual-ion battery. J Energy Chem, 2022, 64: 166-171

39 Maccario M, Croguennec L, Wattiaux A, et al. C-containing $\mathrm{LiFePO}_{4}$ materials-Part I: Mechano-chemical synthesis and structural characterization. Solid State Ion, 2008, 179: 2020-2026

40 Castro L, Dedryvère R, El Khalifi M, et al. The spin-polarized electronic structure of $\mathrm{LiFePO}_{4}$ and $\mathrm{FePO}_{4}$ evidenced by in-lab XPS. J Phys Chem C, 2010, 114: 17995-18000

41 Hou BH, Wang YY, Ning QL, et al. Dual-carbon enhanced FeP nanorods vertically grown on carbon nanotubes with pseudocapacitanceboosted electrochemical kinetics for superior lithium storage. Adv Electron Mater, 2019, 5: 1900006

42 Zhang M, Garcia-Araez N, Hector AL. Understanding and development of olivine $\mathrm{LiCoPO}_{4}$ cathode materials for lithium-ion batteries. J Mater Chem A, 2018, 6: 14483-14517

43 Longoni G, Panda JK, Gagliani L, et al. In situ $\mathrm{LiFePO}_{4}$ nano-particles grown on few-layer graphene flakes as high-power cathode nanohybrids for lithium-ion batteries. Nano Energy, 2018, 51: 656-667

44 Li F, Liu Z, Shen J, et al. A nanorod-like Ni-rich layered cathode with enhanced $\mathrm{Li}^{+}$diffusion pathways for high-performance lithium-ion batteries. J Mater Chem A, 2021, 9: 2830-2839

45 Pender JP, Jha G, Youn DH, et al. Electrode degradation in lithium-ion batteries. ACS Nano, 2020, 14: 1243-1295

46 Zhang H, Yang Y, Ren D, et al. Graphite as anode materials: Fundamental mechanism, recent progress and advances. Energy Storage Mater, 2021, 36: 147-170

47 Zhang $\mathrm{M}$, Song $\mathrm{X}, \mathrm{Ou} \mathrm{X}$, et al. Rechargeable batteries based on anion intercalation graphite cathodes. Energy Storage Mater, 2019, 16: 65-84

48 Hao J, Li X, Song X, et al. Recent progress and perspectives on dual-ion batteries. EnergyChem, 2019, 1: 100004

49 Liu H, Strobridge FC, Borkiewicz OJ, et al. Capturing metastable structures during high-rate cycling of $\mathrm{LiFePO}_{4}$ nanoparticle electrodes. Science, 2014, 344: 1252817

50 Wang $\mathrm{H}$, Wang $\mathrm{R}$, Liu L, et al. In-situ self-polymerization restriction to form core-shell $\mathrm{LiFePO}_{4} / \mathrm{C}$ nanocomposite with ultrafast rate capability for high-power Li-ion batteries. Nano Energy, 2017, 39: 346-354

Acknowledgements This work was supported by the National Natural Science Foundation of China (52173246 and 91963118) and the 111 Project (B13013).

Author contributions Wu XL contributed the concept; Du KD and Meng YF prepared the materials and performed the experiments; Zhao XX and Wang XT supervised the revision of the paper; Luo XX and Zhang W finished the theoretical calculation; $\mathrm{Du} \mathrm{KD}$ and $\mathrm{Wu} \mathrm{XL}$ wrote the paper; $\mathrm{Wu} \mathrm{XL}$ supervised the analysis of the whole work. All authors took part in the general discussion.

Conflict of interest The authors declare that they have no conflict of interest.

Supplementary information version of the paper.

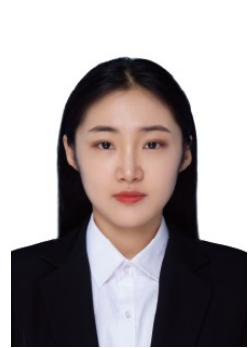

Kai-Di Du received her bachelor's degree from Hebei Normal University in 2019. Now she is pursuing her master's degree under the supervision of professor Xing-Long $\mathrm{Wu}$ at the Department of Chemistry, Northeast Normal University. Her research interests focus on the recovery and reuse of spent lithium-ion batteries

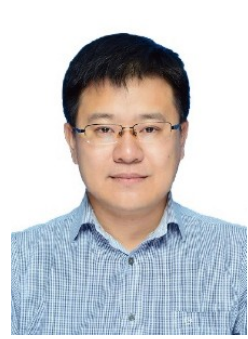

Xing-Long $\mathbf{W u}$ is currently a professor at the Northeast Normal University, China. He received his PhD degree from the Institute of Chemistry, Chinese Academy of Sciences (ICCAS), in 2011. After continuing a two-year postdoctoral work in ICCAS, he moved to the Northeast Normal University as an associate professor in 2013 and became a full professor in 2018. His current research interests focus on high-performance materials for advanced secondary batteries such as $\mathrm{Na} / \mathrm{K} / \mathrm{Li}$-ion batteries and dual-ion batteries, as well as the reuse and recycle of spent $\mathrm{Li}$ ion batteries.

\section{废旧磷酸铁锂电池的正负极同步再利用策略}

杜凯迪 ${ }^{1 \dagger}$, 孟云峰 ${ }^{1 \dagger}$, 赵欣欣 ${ }^{1}$, 王晓形 ${ }^{2}$, 罗晓䂀 ${ }^{1}$, 张薇 ${ }^{1}$, 吴兴隆 $1,2^{*}$

摘要 考虑到废旧锂离子电池对环境、资源和全球可持续性发展存在 严重的威胁和挑战，有必要开发出合适的回收技术实现废旧锂离子电 池的回收和再利用. 因此, 我们提出了一种全新的绿色高效的直接回收 方法, 实现了废旧磷酸铁锂电池中正极 $\mathrm{LiFePO}_{4}$ (LFP) 和负极石墨的双 重回收, 并将其按不同比例复合设计了一种新型双离子电池(DIB)的复 合正极材料 $\left(\mathrm{LiFePO}_{4}\right.$ /石墨, 简写为LFPG). 这种复合正极能够实现阴离 子和阳离子的共同参与脱嵌，从而贡献更高的容量. 结合LFP的高容 量、高稳定性和石墨的高导电性、高电压性, 这种复合正极表现出优 异的电化学性能. 在不同配比的复合材料中, LFP:graphite = 3:1的复合 材料在 $25 \mathrm{~mA} \mathrm{~g}^{-1}$ 的电流密度下展示出接近 $130 \mathrm{~mA} \mathrm{~h} \mathrm{~g}^{-1}$ 的可逆容量, 达 到 $4.95 \mathrm{~V}$ 的高电压平台, 并表现出优异的循环性能(在 $100 \mathrm{~mA} \mathrm{~g}^{-1}$ 的电流 密度下进行700次循环后仍具有良好的容量保持率), 倍率性能相比回 收的单一 $\mathrm{LiFePO}_{4}$ 也得到明显提升. 通过电极动力学研究, 揭示了 $\mathrm{Li}^{+}$和 $\mathrm{PF}_{6}{ }^{-}$在复合正极中的特定扩散行为, 进一步阐明了 $\mathrm{DIB}$ 的阴/阳离子分 阶段嵌入/脱出的工作机理. 本研究为废旧锂离子电池正极和负极材料 的大规模回收提供了一种新的策略, 并为利用废锂离子电池设计出性 能优良的新型复合型锂离子电池正极材料提供了指导. 